\title{
The Efficacy of Quadruple Therapy in Eradication of Helicobacter pylori in Cases of Duodenal Ulcer
}

A Kefeli ${ }^{1}, \mathrm{~S}$ Basyigit ${ }^{2}$, AO Yeniova ${ }^{2}$, Z Asilturk $^{2}$, M Uzman $^{2}$, Y Nazligul $^{2}$

\begin{abstract}
Background: Helicobacter pylori (H. pylori) is an important cause of duodenal ulcer (DU) and eradication this infection can prevent complication related to DU and recurrence of the DU. Quadruple therapy (QT) is one of the recommended treatment regimen for the H. pylori eradication. But there has not been enough data for impact of the QT on eradication success of the H. pylori in patients with DU. We aimed to investigate success of QT in H. pylori positive patients with DU.
\end{abstract}

Method: We included 140 patients who had DU and histology proven $\mathrm{H}$. pylori infection into the study. All patients were given a quadruple therapy program for 14 days consisting of colloidal

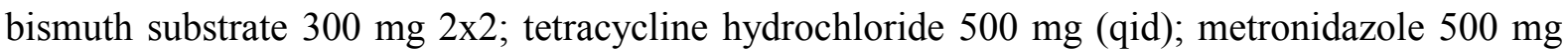
(tid) and a proton pump inhibitor (PPI) (bid) randomly which esomeprazole $20 \mathrm{mg}$ for patients in group 1 (ETMB), lansoprasol $30 \mathrm{mg}$ for group 2 (LTMB), pantoprazole $40 \mathrm{mg}$ for group 3 (PTMB) and rabeprazole $20 \mathrm{mg}$ for group 4 (RTMB). Eradication rate was measured by urea breath test at least 6 weeks after the end of the treatment

Results: Average eradication rate was $78.8 \%$ in ITT analysis (\%95 CI $0.71-0.84)$ and $81.8 \%$ in PP analysis for all groups (\% 95 CI $0.74-0.87$ ). There was no significant differences between different PPI groups.

Conclusion: In patients with DU and H. pylori infection, QT can provide an acceptable but not enough successful eradication success.

Keywords: Duodenal ulcer, Helicobacter pylori, quadruple therapy

From ${ }^{1}$ Department of Gastroenterology, Siirt State Hospital, Siirt, and ${ }^{2}$ Department of Gastroenterology Kecioren Research and Training Hospital, Ankara, Turkey.

Correspondence: Sebahat Basyigit, Kecioren Research and Training Hospital, Department of Gastroenterology, Ankara, Turkey. Fax:+903123569003, e-mail: sbuyuktemiz@yahoo.com. 


\section{INTRODUCTION}

Helicobacter pylori (H. pylori) is the most common infection worldwide. It is also an important cause of certain health problems such as gastric ulcer, duodenal ulcer (DU), gastric lymphoma, gastric adenocarcinoma (1-3). Eradication of this infection has a significant importance for public health.

Since the clarithromycin resistance of the bacteria has been increasing worldwide, Maastricht IV consensus recommended quadruple therapy (QT) which contains bismuth salts, tetracycline, metranidazole and one of the proton pump inhibitor molecule for $\mathrm{H}$. pylori eradication as a first line therapy in regions in which the clarithromycin resistance rate is more than $15-20 \%(4)$.

H.pylori positivity has reached up to $95 \%$ in cases of DU (1-3) and it is important to eradicate this infection to prevent complication related to DU and recurrence of the DU. But there has not been enough data for impact of the QT on eradication success of the H.pylori in patients with DU. In this prospective study, we aimed to investigate success of QT in $\mathrm{H}$. pylori positive patients with DU. Our secondary aim is also to compare eradication rates with different PPIs in H. pylori eradication.

\section{MATERIAL AND METHOD}

This prospective, single center study was approved by the Institutional Review Board and performed between February 2010 and June 2011 in consistent with the Helsinki Declaration. Patients were considered eligible for the study if they had DU with histology-proven $\mathrm{H}$. Pylori infection. Exclusion criteria included recent use of antibiotic or bismuth salts or proton-pump inhibitors in the last 2 months before the study, chronic use of nonsteroidal antiinflammatory drugs or corticosteroids, severe comorbid diseases, pregnancy or lactation, 
diarrhoea, prior gastric surgery, and allergy to any of the drugs in the current treatment. Informed consent was obtained from each patient before enrolling into the study.

The patients were randomly divided into 4 groups. All patients were given a quadruple therapy program for 14 days consisting of colloidal bismuth substrate $300 \mathrm{mg}$ ( equivalent to Bi 2 O3 $120 \mathrm{mg}$; two swallowed tablets, an hour before breakfast and dinner); tetracycline hidrochloride $500 \mathrm{mg}$ (q.i.d., an hour after meals and at bedtime, with ample amount of water); metronidazole $500 \mathrm{mg}$ (t.i.d., after meals) and PPI (b.i.d., 30 minutes before meals) which esomeprazole $20 \mathrm{mg}$ for patients in group 1 (ETMB), lansoprasol $30 \mathrm{mg}$ for group 2 (LTMB), pantoprazole $40 \mathrm{mg}$ for group 3 (PTMB) and rabeprazole $20 \mathrm{mg}$ for group 4 (RTMB).

Detailed written treatment protocol was given to all patients to prevent misuasage medications. Compliance was defined as being taken prescribed drugs more than $90 \%$. .They were actively interviewed about side effects and compliance using a structured questionnaire 1 week after the end of the treatment.

Eradication rate was measured by urea breath test (UBT) at least 6 weeks after the end of the treatment. The C14-UBT was used for this purpose. Patients were informed about not using PPI, H2 receptor blocker, antibiotic and analgesic within one week before to UBT in order to avoid false negativity. After an overnight fasting, $37 \mathrm{kBq}(1 \mathrm{mCi})$ of $\mathrm{C} 14 \mathrm{urea} / \mathrm{citric}$ acid composition (Helicap, Noster System AB, Stockholm, Sweden) with $250 \mathrm{~mL}$ of water was given to patients orally. Breath samples were collected with a dry-cartridge system (Heliprobe Breath Card, Noster System AB). A small desktop Geiger-Muller counter (Heliprobe an alyzer, Noster System AB) was used for the analysis. Results were given both as counts per minute $(\mathrm{CPM})$ and as grade $(0$ : notinfected, $\mathrm{CPM}<25 ; 1$ : equivocal, $\mathrm{CPM} 25-$ 50; 2: infected, $\mathrm{CPM}>50$ ), as suggested by the manufacturer.

Statistical Analysis: 
Both "per-protocol" (excluded patients with poor compliance of therapy and patients with unavailable data after therapy) and "intention-to-treat" (included all eligible patients enrolled into the study regardless of compliance with the study protocol; patients with unavailable data are assumed to have been unsuccessfully treated) analyses were used to evaluate H.pylori eradication. Statistical analyses were performed by using Statistical Package for the Social Sciences (SPSS 15.0) Program. Categorical variables were presented as percentages or counts and continuous variables were presented as mean and standard deviation in descriptive analysis. Kruskal Wallis test was used to compare eradication rates between groups. Results were evaluated at 95\% confidence interval calculated with Wilson's method, and significance was evaluated for each parameter at $\mathrm{p}$ value $<0.05$.

\section{RESULTS}

After exclusion of unsuitable patients according to exclusion criteria, 137 patients (70 male, 67 female) were included in the study and 132 (68 male, 64 female) patients completed the study. Five patients ( 2 male, 3 female) discontinued therapy protocol because of side effects (Table 1). Treatment was stopped because of the adverse effects in these five incidents (abdominal pain in one male and one female patient; amoxicillin related diarrhoea in one male patient and nausea in two female). These side effects were reversible and resolved after the cessation of the related medication.

According to the results of interviews with patients and evaluation of the questionnaires, the patients tolerated the treatment very well. The most common side effects were loose stool/diarrhoea, abdominal pain and malaise. There was not any morbidity that requires hospitalization or mortality related to the treatment. 
Baseline demographic data of the four groups were comparable as shown in Table 1. The number of patients for each group was similar. The age and sex distribution were not significantly different between groups (Table 1).

Average eradication rate was $78.8 \%$ in ITT analysis $(n=137 \% 95$ CI $0.71-0.84)$ and $81.8 \%$ in PP analysis for all study group ( $\mathrm{n}=132, \% 95$ CI $0.74-0.87)$. ITT analysis showed that H. pylori was eradicated in $82.8 \%$ of patients in the ETMB group, in $80.0 \%$ of patients in the LTMB group, in $80.0 \%$ of patients in the PTMB Group, and in $71.8 \%$ of patients in the RTMB Group. Eradication rates were $85.3 \%, 84.8 \%, 80.0 \%$, and $76.7 \%$ in the ETMB, LTMB, PTMB, RTMB groups, respectively in PP analysis. The differences between eradication rates of four treatment regimens were not statistically significant $(p>0.05)$ (Table 1).

\section{DISCUSSION}

In the present study, Bismuth containing quadruple therapy was given to $\mathrm{H}$. pylori positive patients with DU for 14 days. Four different PPI molecules were used for each group, it was a well tolerable treatment and total eradication rate was $81.8 \%$ PP which is an acceptable level but not successful enough.

There are many schemes for treating H. pylori infection, but the best treatment model has not been defined yet, and there is not a single antibiotic treatment that can eradicate it. Historically, a combination of various antibiotics has been used to eradicate this infection. Maastricht IV recommends the QT in the regions which show high resistance to clarithromycin above $15-20 \%$ (4).

Although some local studies, mostly from China, has reported that the eradication rate has been still above 90\%, with QT (6-7). It has been showing differences in different regions. 
ITT ratios have been reported to be $64 \%, 71,6 \%, 72 \%$ in the studies from Greece, Korea, India respectively which used PPI (bid), bismuth (bismuth substrate $300 \mathrm{mg}$, qid or colloidal bismuth substrate $120 \mathrm{mg}$ q.i.d.), metronidazole (500 mg, t.i.d.), and tetracycline (500 mg, qid) protocol for 7 or 10 days (8-10) and recently performed meta-analyses showed that treatment success has been decreasing day after day [11-12]. The result of our study is consistent with the results reported in developing countries. There are also similar results from our country which reported that eradication rates were under $80 \%$ (13-17). Pathogenesis of $\mathrm{H}$. pylori infection depends on the virulence factor of the bacteria and host immune system. It is known that H.pylori is very common in developing countries. Regional differences in terms of virulence factors of $\mathrm{H}$. pylori and differences in host defense mechanisms according to socio-economic and nutritional status can be suggested as possible causes of these controversial results. Different sources of the antibiotics may also be other possible reason for regional differences.

One of the most important factors which affect the eradication success is antibiotic resistance. While alternative treatment modalities have been developed to deal with increased claritromycin resistance, resistance to other antibiotics has risen recently. The prevalence of antibiotic resistance varies considerably from region to region and is related to the habit of using antibiotics. Metronidazole resistance is very high worldwide. In Turkey, metronidazole resistance was reported to be more than $40 \%$ in a study. This resistance rate is much higher than clarithromycin resistance which is reported to be more than $30 \%$ in our country $(8,18$ 20). While the choice of treatment depends on the clarithromycin resistance, this high metronidazole resistance in developing countries should not be ignored.

Tetracycline resistance is also increasing day by day in different countries. Camargo et al have reported that tetracycline resistance was 6\% in Latin America in 2014 (21). Siavoshi et al have reported that tetracycline resistance reached up to $38.1 \%$ from $0.7 \%$ in 
three years in Iran (22). Although antibiotic susceptibility test was not carried out in this study, previous in vitro studies from our country have reported that tetracycline resistance has been $3.2 \%$ in 2000 (23); but it has reached up to $9.1 \%$ in 2012 (19-20). This increasing incidence of tetracycline and metronidazole resistance in $\mathrm{H}$. pylori is a serious concern as it negatively affects the efficacy of quadruple regimen.

Another possible reason of unsatisfactory eradication success can be diversity in terms of drug administration modality in our study. We recommended our patients to use tetracycline after meal instead of with meals for preventing nausea and change in taste sensation in mealtime. This practise may affect bioavailability of the drug.

Differences in mucosal damage of the patients between the study groups (such as duodenal ulcer, gastric ulcer, non-ulcer dyspepsia) may affect the results. Bacteria have numerous of virulence factors. The best known and the most potent of these factors are cagA, vacA, dupA which were shown to be responsible in pathogenesis of DU. These factors are also reported to influence the eradication rate by causing high resistance profiles $(24,25)$. In this study, although virulence factor have not been studied, all of the patients have DU and this can be accepted as an affecting factor for eradication rate according to the information obtained from previous studies. In the literature, most of the studies about quadruple treatment have not aimed at patients with only DU. Only one study is available about this issue in Turkey and the results of this study are reported below $80 \%$ (26).

In this study, we evaluated also the role of different PPI molecules on eradication rates by dividing study population into four groups according to received PPI molecule. PPI's are destroyed in the liver by cytochrome P450 enzymes (27) and may affect metabolism of other drugs which are in combination. The clearance of rabeprazole is non-enzymatically at a higher rate (27). These positive pharmacodynamic and pharmacokinetic features of rabeprazole have led to the idea that efficiency of other drugs is not affected in protocol 
which contains rabeprazole and its efficacy on H.pylori eradication has been greater than other molecules. However, studies have showed no significant differences in eradication rates between protocols which contain different PPIs. Consistent with other studies, we have showed that different PPI molecules did not affect the eradication rate (28).

This study has some limitaitons. It concerns a single centre and includes a relatively small number of subjects and it does not include antibiotic susceptibility testing. But this study is important for alerting decreased eradication rate with bismuth containing QT and possible increase in tetracycline resistance.

In conclusion, tetracycline and metronidazole resistance is increasing in our country. Therefore, the eradication chances with quadruple therapy are likely to decrease in the near future. In addition, since the patients with DU were infected with more virulent H. pylori strains, the eradication of this subject is a more serious problem. Disease and region specific treatment schemes must be developed considering the regional differences in the character of H. pylori infection and habits of antibiotic use of countries. Although metabolism of PPIs were different, they did not affect the success of eradication. 


\section{REFERENCES}

1. Cave DR. Transmission and epidemiology of Helicobacter pylori. Am J Med 1996; 100: 7.

2. Pounder RE, Ng D. The prevalence of Helicobacter pylori infection in different countries. Aliment PharmacolTher 1995; 9: 33-9.

3. Wyle FA. Helicobacter pylori: Current perspectives. J Clin Gastroenterol 1991; 13: $114-24$.

4. Maltfertheiner P, Megraud F, O'morain C, Atherton J, TR Axon A, Bazzoli F et al. (ESHG). Management of Helicobacter pylori infection. The Maastricht IV Consensus Report. Gut 2012; 61: 646-64

5. Onder G, Aydin A, Akarca U, Tekin F, Ozutemiz O, Ilter T. High Helicobacter pylori resistance rate to clarithromycin in Turkey. J Clin Gastroenterol 2007; 41: 747-50.

6. O'morain C, Borody T, Farley A, De Boer WA, Dallaire C, Schuman, R et al. Efficacy and safety of single-triple capsules of bismuth biskalcitrate, metronidazole and tetracycline, given with omeprazole, for the eradication of Helicobacter pylori: an international multicentre study. Aliment Pharmacol Ther 2003; 17: 415-20

7. Liang X, Xu X, Zheng Q, Zhang W, Sun Q, Liu W et al. Efficacy of BismuthContaining Quadruple Therapies for Clarithromycin, Metronidazole, and Fluoroquinolone Resistant Helicobacter pylori Infections in a Prospective Study. J Clin Gastroenterol 2013; 11: 802-7.

8. Pai CG, Thomas CP, Biswas A, Rao S, Ramnarayan K. Quadruple therapy for initial eradication of Helicobacter pylori in peptic ulcer: comparison with triple therapy. Indian J Gastroenterol 2002; 22: 85-7.

9. Mantzaris GJ, Petraki K, Archavlis E, Amberiadis P, Christoforidis P, Kourtessas D. et al. Omeprazole clarithromycin triple therapy versus omeprazole bismuth quadruple 
therapy for healing duodenal ulcer and eradication of Helicobacter pylori infection: a 24 month follow-up study. Eur J Gastroenterol Hepatol 2002; 14: 1237-43.

10. Jang HJ, Choi MH, Kim YS, Seo YA, Baik KH, Baik IH et al. Effectiveness of triple therapy and quadruple therapy for Helicobacter pylori eradication. The Korean $\mathbf{J}$ Gastroenterol 2005; 46: 368-72.

11. Venerito M, Krieger T, Ecker T, Leandro G, Malfertheiner P. Meta-analysis of bismuth quadruple therapy versus clarithromycin triple therapy for empiric primary treatment of Helicobacter pylori infection. Digestion 2013; 88: 33-45.

12. Luther J, Higgins PD, Schoenfeld P S, Moayyedi P, Vakil N, Chey WD. Empiric quadruple vs. triple therapy for primary treatment of Helicobacter pylori infection: systematic review and meta-analysis of efficacy and tolerability Am J Gastroenterol 2010; 105: 65-73.

13. Dogan E, Kefeli A, Nazligul Y, Yeniova AO, Kucukazman M, Cizmeci Z et al. AntiCagA positivity in duodenal ulcer and functional dyspepsia patients infected with Helicobacter pylori and its effect on the outcome of eradication treatment. Dicle Med J 2011; 38: 7-11.

14. Kadayifci A, Uygun A, Polat Z, Kantarcioğlu M, Kılcıler G, Başer O et al. Comparison of bismuth-containing quadruple and concomitant therapies as a first-line treatment option for Helicobacter pylori. Turk J Gastroenterol 2012; 23: 8-13.

15. Uygun A, Kadayifci A, Safali M, Ilgan S, Bagci S. The efficacy of bismuth containing quadruple therapy as a first-line treatment option for Helicobacter pylori. J Dig Diseases 2007; 8: 211-5.

16. Uygun A, Ozel A. M, Yildiz O, Aslan M, Yesilova Z, Erdil A et al. Comparison of three different second-line quadruple therapies including bismuth substrate in Turkish 
patients with non-ulcer dyspepsia who failed to eradicate Helicobacter pylori with a 14-day standard first-line therapy. J Gastroenterol Hepatol 2008; 23: 42-5.

17. Özden A, Seven G, Bektas M. Effectiveness of different treatment regimens in Helicobacter pylori eradication; Ten years' experience of a single institution. Turk $\mathbf{J}$ Gastroenterol 2010; 21: 218-23.

18. Bakir Ozbey S, Ozakin C, Keskin M. Antibiotic resistance rates of Helicobacter pylori isolates and the comparison of E-test and fluorescent insitu hybridization methods for the detection of Clarithromycin resistant strains. Mikrobiyol Bul 2009; 43: 227-34.

19. Aygul K. The Isolation of Helicobacter pylori from Antral Biopsy Specimens and Antibiotic Susceptibility. Van, Yuzuncu Yil Uni Pub 2006; 17: 38-42.

20. Cagdas U, Otag F, Tezcan S, Sezgin O, Aslan G, Emekdas G. Detection of Helicobacter pylori and antimicrobial resistance in gastric biopsy specimens. Mikrobiyol bul 2012; 46: 398-409.

21. Camargo MC, García A, Riquelme A, Otero W, Camargo CA, Hernandez-García T, et al. The Problem of Helicobacter pylori Resistance to Antibiotics: A Systematic Review in Latin America. Am J Gastroenterol 2014; 109: 485-95.

22. Siavoshi F, Saniee P, Lati-Navid S, Massarrat S, Sheykholeslami A. Increase in Resistance Rates of H. pylori Isolates to Metronidazole and Tetracycline Comparison of Three 3-Year Studies. Arch of Iran Med (AIM) 2010; 13: 117.

23. Kantarceken B, Yıldırım B, Karıncaoğlu M, Aladağ M, Hilmioglu F. Helicobacter pylori and antibiotic resistance. Turk J Gastroenterol 2000; 11: 141-5.

24. Sugimoto M, Yamaoka Y. Virulence factor genotypes of Helicobacter pylori affect curerates of eradication therapy. Arch. Immunol. Ther Exp 2009; 57: 45-56 
25. Shiota S, Nguyen LT, Murakami K, Kuroda A, Mizukami K, Okimoto T et al. Association of Helicobacter pylori dupA with the failure of primary eradication. $\mathrm{J}$ Clin Gastroenterol 2012; 46: 297.

26. Gumurdulu Y, Serin E, Ozer B, Kayaselcuk F, Ozsahin K, Cosar AM et al. Low eradication rate of Helicobacter pylori with triple 7-14 days and quadruple therapy in Turkey. World J Gastroenterol 2004; 10: 668-71.

27. Padol S, Yuan Y, Thabane M, Padol IT, Hunt RH. The effect of CYP2C19 polymorphisms on H. pylori eradication rate in dual and triple first line PPI therapies. Am J Gastroenterol 2007; 101: 1467-75.

28. Altintas E, Sezgin O, Ulu O, Aydin O, Camdeviren H. Maastricht II treatment scheme and efficacy of different proton pump inhibitors in eradicating Helicobacter pylori. World J of Gastroenterol 2004; 10: 1656-8. 
Table 1: Demographic and Clinical Characteristics of Study Group

\begin{tabular}{lllll}
\hline Parameters & $\begin{array}{l}\text { ETMB } \\
(\mathbf{n}: 35)\end{array}$ & $\begin{array}{l}\text { LTMB } \\
(\mathbf{n : 3 5})\end{array}$ & $\begin{array}{l}\text { PTMB } \\
(\mathbf{n : 3 5})\end{array}$ & $\begin{array}{l}\text { RTMB } \\
(\mathbf{n : 3 5})\end{array}$ \\
\hline Age (year) & $33.4 \pm 15.2$ & $32.9 \pm 14.9$ & $32.6 \pm 13.8$ & $33.5 \pm 15.3$ \\
Gender & & & & \\
\multicolumn{1}{l}{$\begin{array}{l}\text { Male (n,\%) } \\
\text { Female (n,\%) }\end{array}$} & $19(54.3 \%)$ & $15(42.9 \%)$ & $18(51.4 \%)$ & $18(51.4 \%)$ \\
ITT & $16(45.7 \%)$ & $20(57.1 \%)$ & $17(48.6 \%)$ & $17(48.6 \%)$ \\
PP & $82.8 \%$ & $80 \%$ & $80 \%$ & $71.8 \%$ \\
& $85.3 \%$ & $84.3 \%$ & $80 \%$ & $76.7 \%$
\end{tabular}

Side effect

\begin{tabular}{lllll} 
Diarrhea & 1 & 1 & 0 & 1 \\
Abdominal pain & 0 & 1 & 0 & 1 \\
\hline
\end{tabular}

Abbrevations: ITT: Intenton to treatment, PP: Per protocol, ETMB: esomeprazoletetracycline-metranidazol-bismuth, LTMB: lansoprazole- tetracycline-metranidazol-bismuth, PTMB: pantoprazole- tetracycline-metranidazol-bismuth, RTMB: rabeprazole- tetracyclinemetranidazol-bismuth 